Open Access

\title{
Assessment of ageing effect on the mechanical behaviour of steel/aluminium self-piercing riveted joint
}

\author{
L. Calabrese ${ }^{1 *}$, E. Proverbio $^{1}$, G. Di Bella ${ }^{2}$, G. Galtieri $^{1}$ and C. Borsellino ${ }^{3}$
}

\begin{abstract}
Background: Self-piercing riveting (SPR) is a new performing technology able to joint several kinds of metal and non-metal supports together. The combined effect of joint configuration and environmental conditions could have detrimental effect on the ageing effect on mechanical behaviour of dissimilar metal SPR joints.

Methods: The joining of dissimilar materials, such as steel and aluminium, realized by self-piercing riveting (SPR) technique was studied to evaluate the ageing effects on its mechanical behaviour in critical environmental conditions. The investigation was carried out on symmetrical or unsymmetrical joints at varying total thicknesses (i.e. 2.0, 2.5 and $3.0 \mathrm{~mm}$ ). The joint resistance was determined by single-lap shear tests. A design of experiment (DoE) has been performed by using Minitab ${ }^{\oplus}$ followed by the statistical analysis (ANOVA) of the experimental data. Long-term ageing tests in salt spray environment were performed to evaluate the durability of the mechanical joint.

Results: The experimental results evidenced that the corrosion degradation phenomena influenced significantly both the performance and failure mechanisms of the joints; also, the joint configuration is a significant factor for the corrosion effect. In the salt spray, the aluminium sheet undergoes a noticeable degradation due to galvanic Al/Fe corrosion. The set characterized by thinner aluminium sheet evidenced a gradual reduction of the mechanical strength with increasing ageing time due to the prevalence of thinning induced by aluminium corrosion. Instead, for S10-A15 samples (characterized by a thicker thickness of aluminium sheet) during the first 7 weeks, stable mechanical performances were observed.

Conclusions: The experimental results evidenced that the corrosion degradation phenomena influence significantly both performances and failure mechanisms of SPR joints. Furthermore, the durability of the SPR joint is strongly affected by the joint configuration, and the best results were observed in the unsymmetrical joint with thicker aluminium sheet.
\end{abstract}

Keywords: Self-piercing riveting; Corrosion; Durability; Single-lap shear test; DoE

\section{Background}

The need to join dissimilar materials with different thicknesses is felt in many fields, such as automotive, aerospace and shipbuilding, where the choice of joining method is generally a compromise of joint structural performance, manufacturing speed and cost (Patrick and Sharp 1992). The mechanical stability of the joints is dependent on many parameters including the strength

\footnotetext{
* Correspondence: Icalabrese@unime.it

${ }^{1}$ Department of Industrial Chemistry and Materials Engineering, Faculty of Engineering, University of Messina, Contrada di Dio, 98166 Messina, Italy Full list of author information is available at the end of the article
}

of the joining technique and nature of assembled materials (Fujita and Mizuno 2007).

The joining of different materials, such as steel and aluminium, has led to technological solutions able to not affect the performances or to introduce physical discontinuity between the substrates. It is not always possible to use conventional joining methods such as spot or arc welding, therefore new performing technologies as laser welding (Zhao et al. 1999), self-riveting (Wood et al. 2011) or clinching (Carle and Blount 1999) methods seem to be possible alternatives. In this sense, the selfpiercing riveting allows cost savings, high resistance and flexibility of the joined structures. Furthermore, the 
absence of heat treatment avoids thermal effects on metals or protective coatings, reduces the microstructural transformations caused by traditional welding technologies and assures both high shear and pull strength. As an example, in automotive industry, SPR is employed to join the aluminium side impact beam with steel sheet stampings.

Another important feature of the self-piercing riveting is the possibility to combine different joining techniques (i.e. mechanical and adhesive-hybrid joints) (Kweon et al. 2006; Barnes and Pashby 2000) and several kinds of metals and non-metals supports together (Fiore et al. 2013a,, b; Borsellino and Di Bella 2008). The combined effect of joint configuration and environmental conditions could have detrimental effect on the mechanical behaviour of dissimilar metal SPR joints. Moroni et al. (2010) have compared simple and hybrid joints in terms of strength, stiffness and energy absorption, evaluating also the influence of some geometrical (thickness, substrates, pitch) and environmental variables. The results of their experimental research have shown that the joint may be mechanically "tailored" on the application depending on design goals and service conditions.

Rivets are often sensible to premature failures induced by corrosion degradation. Heinemeyer and Feldmann (2011) investigated the influence of the rivet corrosion on the durability of connections in great civil structures like bridges. In particular, the results evidenced that the heads of the rivets are subject to heavy corrosion phenomena reducing drastically their mechanical integrity.

Hoang et al. (2011) carried out natural ageing (i.e. after 3 and 30 days) experiments to study the mechanical behaviour of aluminium riveted connections in which the plates were tempered aluminium alloy and the aluminium rivet with two different dies (FM and DZ). It revealed that after 3 days of natural ageing, the strength of the aluminium riveted connections tend to stabilize. Moreover, the tests showed that the strength is influenced by the die geometry especially under pure shear loading conditions.

In order to avoid corrosion phenomena in hybrid joints, metallic materials should be chosen in view of their electrochemical stability and corrosion resistance (Feser and Klose 1999). An appropriate material selection is recommended with the purpose to reduce the electrochemical potential differences and to prevent significant galvanic currents (Calabrese et al. 2014a). Furthermore, the presence of interstitial or overlapped areas in the joints gives rise to the formation of electrolytic cells due to stagnation of electrolyte solution inducing consequently differential aeration corrosion (crevice corrosion). The joining of two different metals as steel/ aluminium increases the risk of corrosion phenomena due to galvanic effects due to a quite different electrochemical behaviour between the two metals (Bardal
2004). In a critical environment, the localized corrosion phenomena occur in the presence of surface irregularities or crevices due to the electrolyte accumulation in the interstices that stimulated metal dissolution in localized regions of the joints. The area affected by corrosion within the overlap increases with time as the electrolyte solution gradually penetrates further toward the centre of the overlap. After a sufficient accumulation of the corrosion products, a loss of direct contact between the metals occurs and this compromises the interlocking of the joint. This problem is present in riveted lap joints of fuselage skin panels being exposed to damage and corrosion fatigue cracks. These last can cause catastrophic failure if not detected and repaired. When the corrosion takes place, the sheets are forced to separate due to the presence of the corrosion products resulting in bulging or pillowing of the overlapped sheets. The latter phenomenon is the feature used to detect corrosion in lap joints by using non-destructive inspection techniques (Okafor and Natarajan 2007; Bellinger et al. 2007). Galvanic corrosion of dissimilar metal joints will reduce joint strength if the joint is unprotected by a coating or by adhesive when subjected to a corrosive environment. A suitable procedure to enhance the corrosion resistance is to use organic or metallic coating to protect the metal substrate (Zheng et al. 2007; Han and Chrysanthou 2008). González-García et al. (2007) have investigated polyurethane polymeric film applied on metallic substrates; this coating showed higher adhesion and enhanced anticorrosion protection characteristics when applied on carbon steel rather than on galvanized steel. HuttunenSaarivirtaa et al. (2011) studied the protective action of two polyimides (PI) coatings on galvanized steel panels evaluating the effect of chemical structure, microstructure and corrosion performance in $0.5 \mathrm{M} \mathrm{NaCl}$ solution. The results evidenced marked differences in electrochemical behaviour of the coatings, which could be primarily explained by the different nanostructures of the polyimidic coatings. In particular, the defect-free PI coating showed a higher and longer protection to corrosion phenomena. Another way to enhance the corrosion resistance is to protect the steel rivet by a zinc coating (Azzerri et al. 1982). Krüger and Mandel (2011) have investigated the galvanic corrosion behaviour of two sheets of the aluminium alloys joined by an electrogalvanized zinc blind rivet made of mild steel in a 5 wt.\% $\mathrm{NaCl}$ solution. Esfahani et al. (2012) have evaluated the effect of laser-assisted self-pierce riveting (LSPR) on the $\mathrm{Zn}$-Sn and $\mathrm{Al}$ coatings of self-piercing rivets to join magnesium sheets. However, although the durability of the SPR joint in a corrosion environment is a known problem (Chrysanthou 2014), few works are reported in the literature with the purpose to better evidence the corrosion aspects of the joint degradation 
and at the same time to enhance the knowledge about the relationship between joint configuration and performance durability in an aggressive environment.

Especially in automotive industry, accelerated corrosion tests are preferred due to economic reasons. The salt spray test is the oldest "corrosion test" and the most widely used. One of the most interesting advantages is that the test is multi-material. For example, it is possible to test a bare material, a painted one and a noble or sacrificial coating. Moreover, the test duration is short compared to the natural environment, the cost is limited and a standardized material is required.

There is a limited number of standards dedicated to this technique, so the framework is widely known. However, this test can unfortunately sometimes lead to elimination of some economic solutions that could be suitable for an application. Or it can even lead to modification of the classification of materials, as a result of creating different mechanisms of corrosion. It is a destructive test, although very scattered and not correlated with actual performance, and it is widely used to investigate the material/structure durability in critical environmental condition.

The aim of the present work is to evaluate the durability in salt spray test (according to ASTM B117) of steel/ aluminium alloy joints, obtained by self-piercing riveting. The joint resistance has been determined by means single-lap shear tests. Four combinations of aluminium alloy/steel thicknesses were investigated; four samples for each combination and for each ageing time were realized; totally, 128 joints were made for each joint configuration. With the purpose to evaluate the effect of each variable on the mechanical performance of the selfpiercing riveted joints, a statistical design of experiment was performed. The results were tested by using the analysis of the variance (ANOVA). The knowledge of these statistical information can be helpful in engineering design to optimize the joining process (properties, materials configuration, thickness...), taking into account the durability in aggressive environmental condition of the joints.

\section{Methods}

\section{Materials and manufacturing}

The investigation has been carried out on single-lap riveted aluminium/steel joints (SLJ). The joints were realized at varying the total thickness $(2.0,2.5$ and $3.0 \mathrm{~mm})$ to inquire about the effect of corrosion on the sheets configuration. All configurations of the SPR joints investigated is reported in Table 1.

The employed materials, their thickness, chemical composition and mechanical properties are reported in Table 2. The rivet and die geometry, shown in Fig. 1, were supplied by the Avdel ${ }^{\circ}$ S.r.l.. The rivets are made in
Table 1 Sheet configurations of single-lap joint samples

\begin{tabular}{lll}
\hline CODE & Upper-steel $[\mathrm{mm}]$ & Lower-aluminium $[\mathrm{mm}]$ \\
\hline S10-A10 & 1 & 1 \\
S15-A15 & 1.5 & 1.5 \\
S10-A15 & 1 & 1.5 \\
S15-A10 & 1.5 & 1 \\
\hline
\end{tabular}

austenitic steel coated with $11-\mu \mathrm{m}$ protective layer. Their Fastriv designation is FSC4865001Z11. The geometry of riveted SLJ is shown in Fig. 2. For all joint combinations, the upper sheet was Carbon Steel A570 and the bottom one was Aluminium AA6082.

The joints were made by an electro-hydraulic riveting system. The duration of the process was about $2 \mathrm{~s}$. The equipment (Textron Fastening System) was supplied by a hydraulic motor $(230 \mathrm{~V}, 50-60 \mathrm{~Hz})$ with an electrohydraulic valve necessary to vary the pressure applied on the punch. The max operation pressure was $630 \mathrm{bar}$; the maximum load was approximately $60 \mathrm{kN}$ and nominal power $750 \mathrm{~W}$. Prior to the riveted sample preparation, several attempts were made at varying the oil pressure to find out the better pressure values for the different thickness configurations. The working pressures were: 280 bar for S10-A10 set, 300 bar for S10-A15 set and 320 bar for the other joint configurations.

In order to define an adequate number of samples, the statistical procedure of DOE was applied. The analysed factors were the sheet thicknesses and the time intervals in which we decided to inquire the joint resistances. In this case, the number of replicas should be $4^{2}$ (Levels ${ }^{\text {Factors }}$ ). To decide if this number lead to a strong DOE, the signal/noise ratio can be evaluated, than the "mean loads"/"standard deviation" ratios have been calculated for similar tests; these last ratios were in the order of $10 \div 40$. From the literature, we found that for a signal/noise ratio lower than 2.8 , the number of replicas should be doubled whereas at increasing the ratio it can be reduced so we decided to reduce the number of replicas to four.

\section{Ageing treatment}

Samples were exposed to critical environmental conditions according to ASTM B117 standard. The salt spray fog had a chemical composition of $5 \% \mathrm{NaCl}$ solution

Table 2 Properties of sheet materials

\begin{tabular}{lll}
\hline Material & AA6082 & Carbon steel A570 \\
\hline Geometry & Thickness: $1-1.5 \mathrm{~mm}$ & Thickness: $1-1.5 \mathrm{~mm}$ \\
Chemical & $\mathrm{Fe}=0.5 \mathrm{Cu}=0.1 \mathrm{Si}=0.5$ & $\mathrm{C}=0.3, \mathrm{Si}=0.25$, \\
composition & $\mathrm{Mn}=0.4 \mathrm{Mg}=0.6-1.2$ & $\mathrm{Mn}=0.8, \mathrm{P}=0.04$ \\
(\% weight) & $\mathrm{Cr}=0.25 \mathrm{Zn}=0.2 \mathrm{Ti}=0.1$ & $\mathrm{Fe}=$ balance \\
& $\mathrm{Al}=$ balance & \\
Hardness & $\mathrm{HBN}_{(2,5 / 62,5 / 30)}=60$ & $\mathrm{HV}=170$ \\
Yield strength $[\mathrm{MPa}]$ & 224 & 590 \\
\hline
\end{tabular}



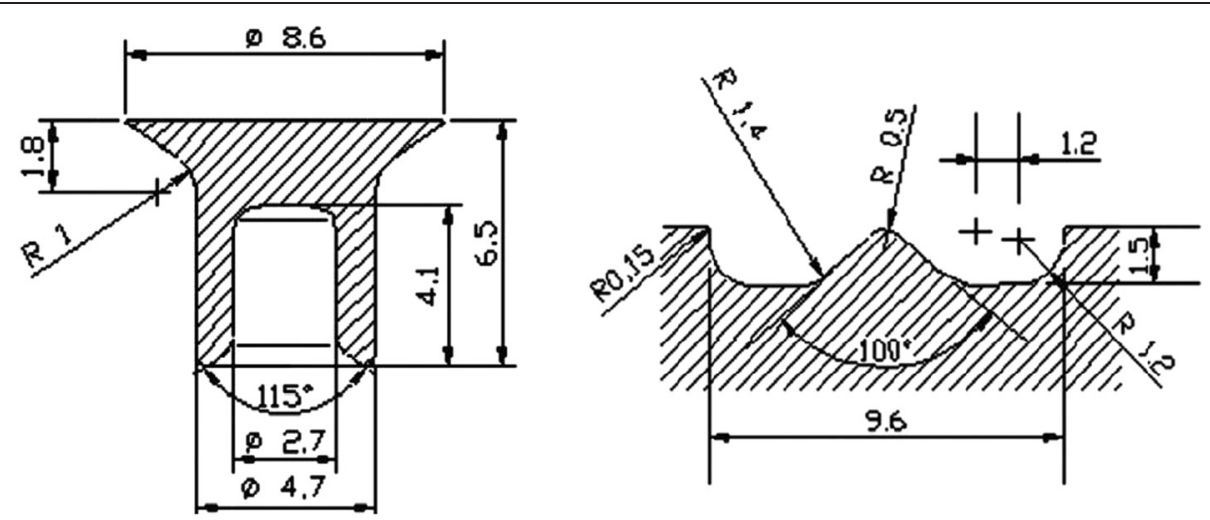

Fig. 1 Geometrical configuration of rivet and die [mm]

( $\mathrm{pH}$ between 6.5 and 7.2). In the climatic chamber, the samples were aged continuously keeping at temperature of $35{ }^{\circ} \mathrm{C}$. This practice provides a controlled corrosive environment.

For each ageing condition and for each configuration, four specimens were removed and then mechanically tested. The removed samples, clean out and dried, were preserved in a sealed plastic storage bag with silica gel desiccant to ensure no further corrosion evolution during storage; moreover, the appropriate actions to avoid the introduction of other variable factors have been taken; such as the control of the environment conditions.

\section{Single-lap shear test}

Shear testing of single-lap joints was performed, according to ISO/CD 12,996, by means of a universal testing machine (Zwick-Roell Z250) equipped with a 50-kN load cell and a crosshead rate of $1 \mathrm{~mm} / \mathrm{min}$ (displacement control test).

\section{Statistical analysis}

To verify if the thickness and ageing time are significant factors that influence the mechanical properties of the joint, a statistical analysis (ANOVA) was performed using Minitab ${ }^{\bullet}$ software. In the following, the two factors "thickness" and "ageing time" are called "thickness" and "weeks", respectively; the first with four levels (1 for S10A10, 2 for S15-A15, 3 for S10-A15 and 4 for S15-A10, see Table 1 ), the second with eight levels ( 1 for 0 week, 2 for 1 week, 3 for 2 weeks, 4 for 3 weeks, 5 for 5 weeks, 6 for 7 weeks, 7 for 10 weeks and 8 for 15 weeks).

\section{Results and discussion}

\section{Single-lap shear tests}

Figure 3 shows the load versus crosshead displacement trends of the single-lap shear tests un-aged joints (Fig. 3a) and 10 weeks aged ones (Fig. 3b). The tensile shear load trends of SPR joints decrease at increasing ageing time in salt spray environment.

Three significant regions can be identified. At first (zone I), the load increases linearly with the crosshead displacement. In this phase the joint resistance is due to two contributions: the friction resistance, resulting from the contact pressure between the aluminium and steel sheets induced by mechanical joining, and the shear resistance offered by the rivet. In this region, where the materials are in elastic regime, the maximum slope of the load-displacement curve is reached. In region II, the samples lose gradually their stiffness due to a bending effect at the edge of the sheets in the overlapping area

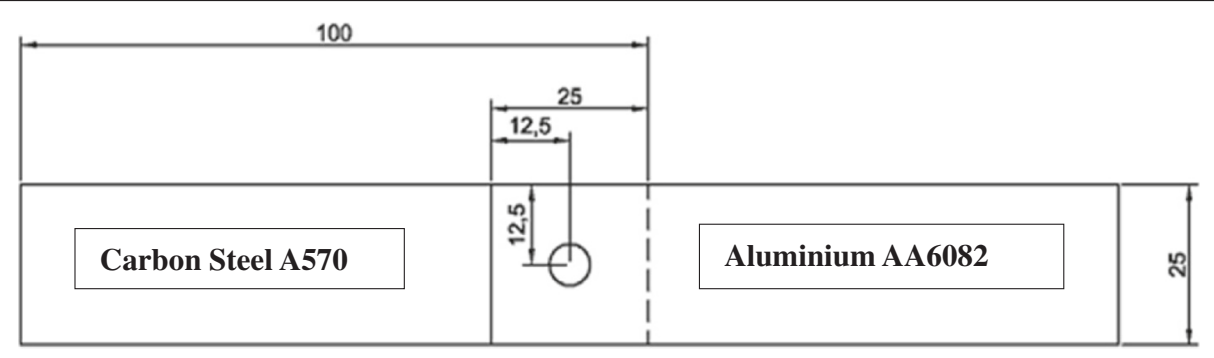

Fig. 2 Single-lap joint geometry $[\mathrm{mm}]$, total length $L=175 \mathrm{~mm}$ 

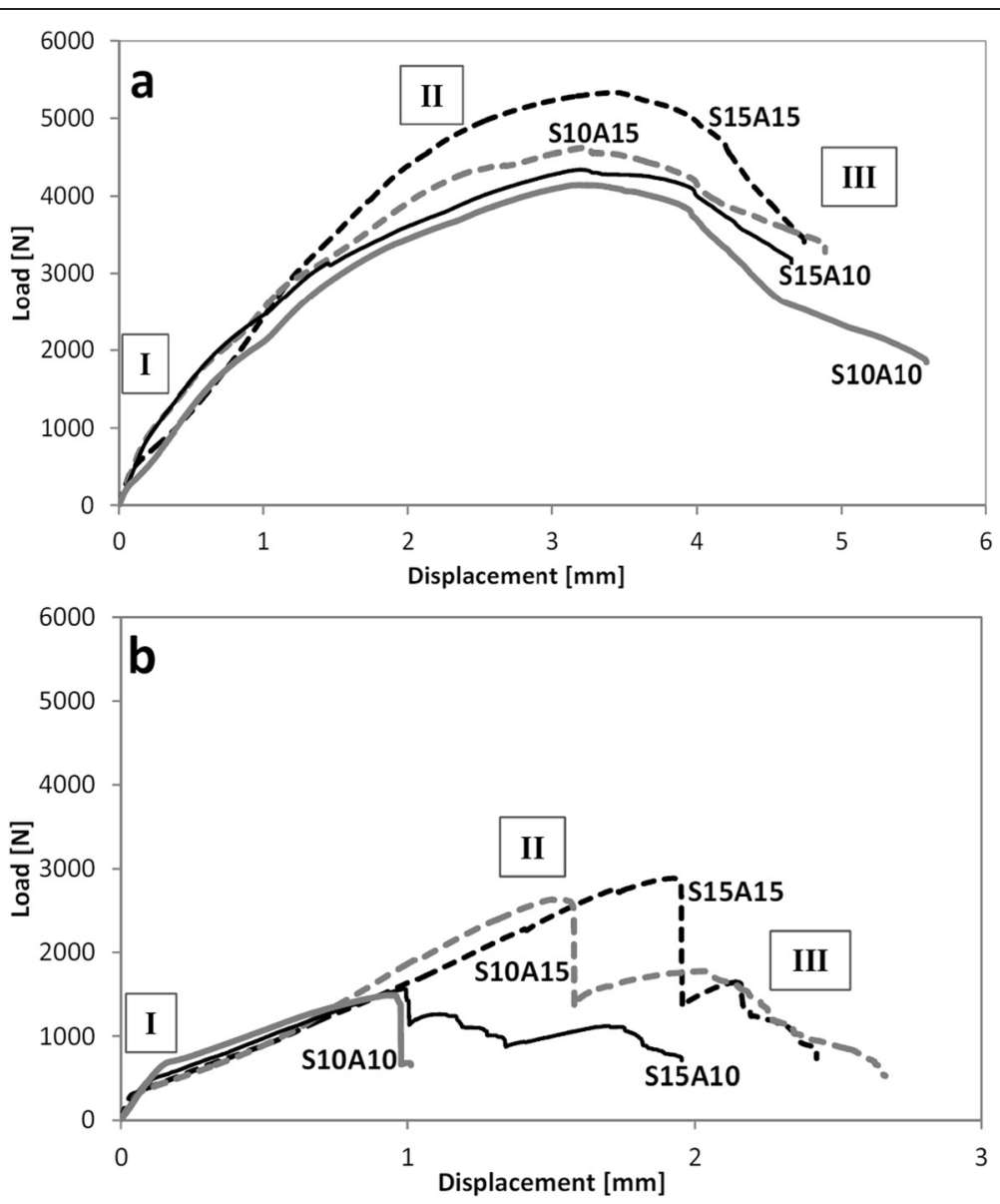

Fig. 3 Load versus displacement trend for each joints configuration at ageing time $\mathbf{a} 0$ week and $\mathbf{b} 10$ weeks

for the unsymmetrical configuration of the single-lap joint. At increasing load, the sheets lose contact of the overlapping area. The friction contributed to the joint stiffness becomes negligible. Consequently, the resistance is offered only by the shear behaviour of the rivet. In this way, the unbuttoning phenomena have started: this fracture type occurs for most of joint batches.

The area around the rivet bottom undergoes large strains such as effects of bearing or rivet pullout in the lower sheet (point A in the Fig. 4). In the upper sheet, instead, the rivet head penetrates steel plate (point B in Fig. 4) and then the joint rupture occurs (Han et al. 2010). For example, in the S10-A10 sample (see Fig. 4) at 0 week, it is possible to notice an enlargement of the aluminium hole, deformed by the rivet tail by bearing (Di Bella and Calabrese 2010).

After the maximum load has been reached, the SPR joint performances progressively are reduced during the test. The mechanical stability of the joints is compromised (zone III), and the $\Delta \mathrm{P} / \Delta \mathrm{L}$ ratio becomes negative

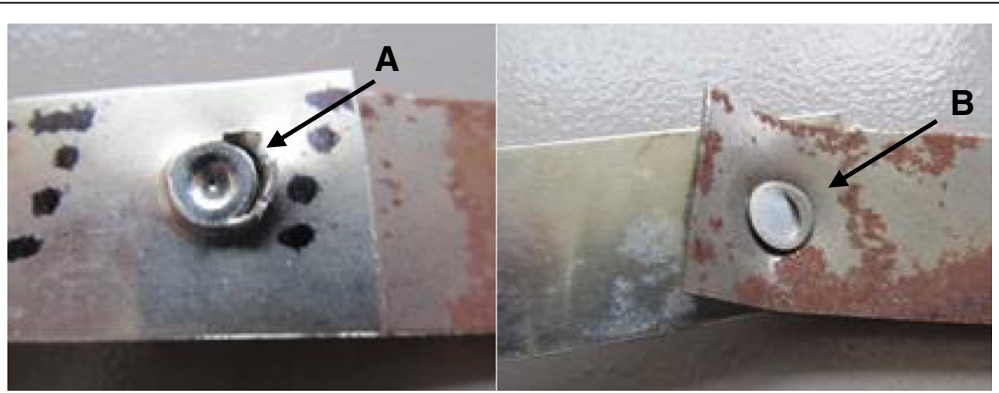

Fig. 4 The tail (left) and head (right) of rivet in S10-A10 joint at 0 week: a) effects of bearing or rivet pullout in the lower sheet; $\mathbf{b})$ the rivet head penetrates steel plate in the upper sheet 


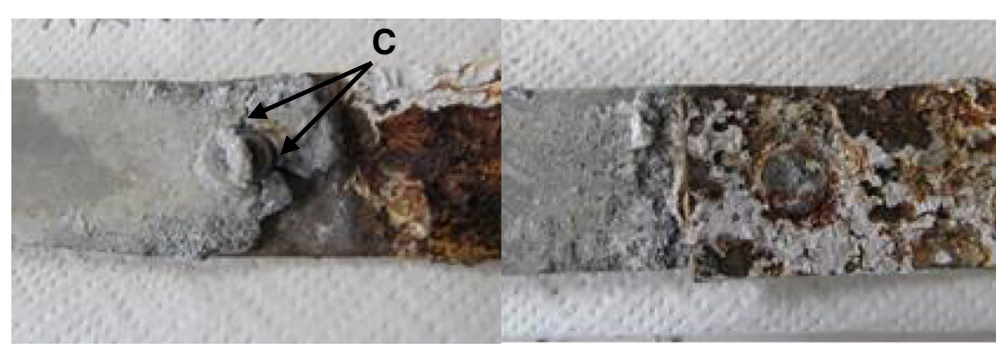

Fig. 5 The tail (left) and head (right) of rivet in S15-A15 joint at 10 weeks: c) crack near the bottom rivet

due to a gradual reduction of the load to very low magnitude level. The rupture of most samples at 0 week was the unbuttoning: the rivet, interlocked into the bottom sheet, is pulled out during the tensile test. The high shear force produces a partial fracture on the rivet head without to obtain its total collapse. The joints, where the thickness of the lower sheet is $1.0 \mathrm{~mm}$, are subject furthermore to bearing failure on the lower sheet.

Among joint configurations where the lower sheet is $1.5 \mathrm{~mm}$ thick, the presence of (circular or radial) cracks on the bottom of the rivet, generated during the manufacturing procedure, gives rise to failure mechanisms such as shear out or net tension (Calabrese et al. 2013; Li et al. 2012; Han et al. 2007).

Figure 5 shows the effects of corrosion at 10 weeks on the S15-A15 joint. The presence of corrosion products weakens the joint and compromises the mechanical interlocking in the overlapping area of the joint promoting the advancement of crack near the bottom rivet (see point $\mathrm{C}$ in Fig. 5). Consequently, with the relevant electrochemical distortion of the aluminium plate, the final failure for net tension occurs prematurely with very low load values. This rupture is due to propagation of cracks located in the rivet tail, following the manufacturing or failure on the lower aluminium sheet. This mechanism could be classified as cleavage failure of the mechanical joint (Valenza et al. 2007). The details about the relationship between the failure mechanisms and the ageing time in salt spray test will be reported later in a specific section.

Also for 10 weeks aged samples (Fig. 3b), it is possible to identify three regions in the load deflection curve. The ageing treatment reduces significantly the performances of the joints favouring the insurgence of premature failure mechanisms induced by localized corrosion phenomena.

With increasing ageing time, both the maximum values of load and the maximum displacement decrease. Such behaviour is shown in Fig. 6 for S10-A10 samples in which are drawn the load/displacement curves at increasing ageing time. The samples undergo in a different way: the effects of the electrochemical activity of metal constituents and the subsequent formation of corrosion products.
The permanence for a long time in the salt spray environment occasionally leads to premature rupture of some joints in climatic chamber just due to the action of its weight force, because in this aggressive environmental condition, the aluminium plate undergoes a noticeable degradation for galvanic corrosion, favouring its rapid thinning (Calabrese et al. 2014b, 2015).

Oxides and hydroxides of $\mathrm{Al}$ (i.e. $\mathrm{Al}_{2} \mathrm{O}_{3}, \mathrm{Al}(\mathrm{OH})_{3}$ ), formed at long ageing times (showing their typical white coloration), induce an increase of volume in the joining area. Thus, the presence of $\mathrm{Al}$ corrosion products influences the interlocking between the aluminium/steel sheets. At first, when the oxide layer is thin, an improvement of the interlocking was observed. When the layer of oxides grows, it influences significantly the failure. In fact, at medium and long ageing times (see Fig. 6 at 5 and 7 weeks), a progressive decrease of the joint strength was observed. In this last case, the brittle fracture of the oxides becomes dominant despite of the interlocking effect, by compromising the resistance in the plastically deformed region of the aluminium button in which the corrosive attack induces the formation of circular cracks on the bottom rivet leading to rupture the joint. For long ageing periods (see Fig. 6 after 7 weeks), the mechanical

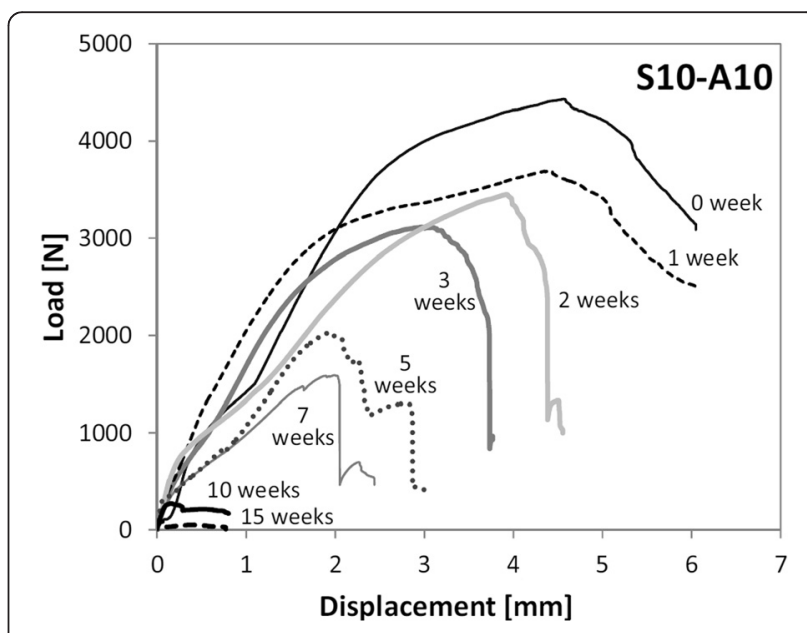

Fig. 6 Load/Displacement curves for S10-A10 samples at increasing ageing time 
joint characteristics are compromised by the relevant dissolution of the aluminium sheet.

With the aim to inquire the reliability of the joints, the ultimate load values of each sample have been ordered from the highest to the lower one at each ageing time; the series of such values have been plotted at varying ageing time. The trends are reported in Fig. 7 for all joint configurations.

The curves with higher load are related to samples with low manufacturing defects, characterized by higher performance and higher mechanical stability to corrosion degradation (I Load). Instead, the lower curves are related to samples sensible to corrosion degradation (IV Load). At long ageing time, some curves disappear from the graph because some samples reach the failure just in the climatic chamber (without single-lap shear test) due to metal dissolution. Consequently, it was not possible to acquire experimentally the failure load.

It is worth noticing the different trends between the S10A15 batch and other ones. The S10-A10 joint configuration has an acceptable resistance (i.e. about $80 \%$ of un-aged sample) at low ageing time (until 2 weeks); afterward, some broken samples were observed at increasing ageing time. At 15 weeks, only one sample was still not broken inside the chamber. A similar behaviour can be observed for S15A10 configurations. Instead, the S15-A15 and S10-A10 sets show higher load value at first ageing weeks (i.e. about $20 \%$ ), due to the effect of the salts thin interlayer that enhances the interlocking between the metal sheets. Then, about the S15-A15 batch, its failure load decreases at increasing the ageing time maintaining, anyway, higher values of about $10 \%$ than the S15-A10 and S10-A10 joints.

Instead, the S10-A15 samples are all mechanically stable and retain comparable load values at increasing ageing time maintaining high performance up to 7 weeks. According to previous considerations, at the substrate interface and around the rivet, the initial deposit of salts generates new points of contact through which the joint increases its resistance. At the same time, the metal dissolution of aluminium (induced by galvanic coupling with steel) favours the thinning of the cross-section of the sheet leading to the
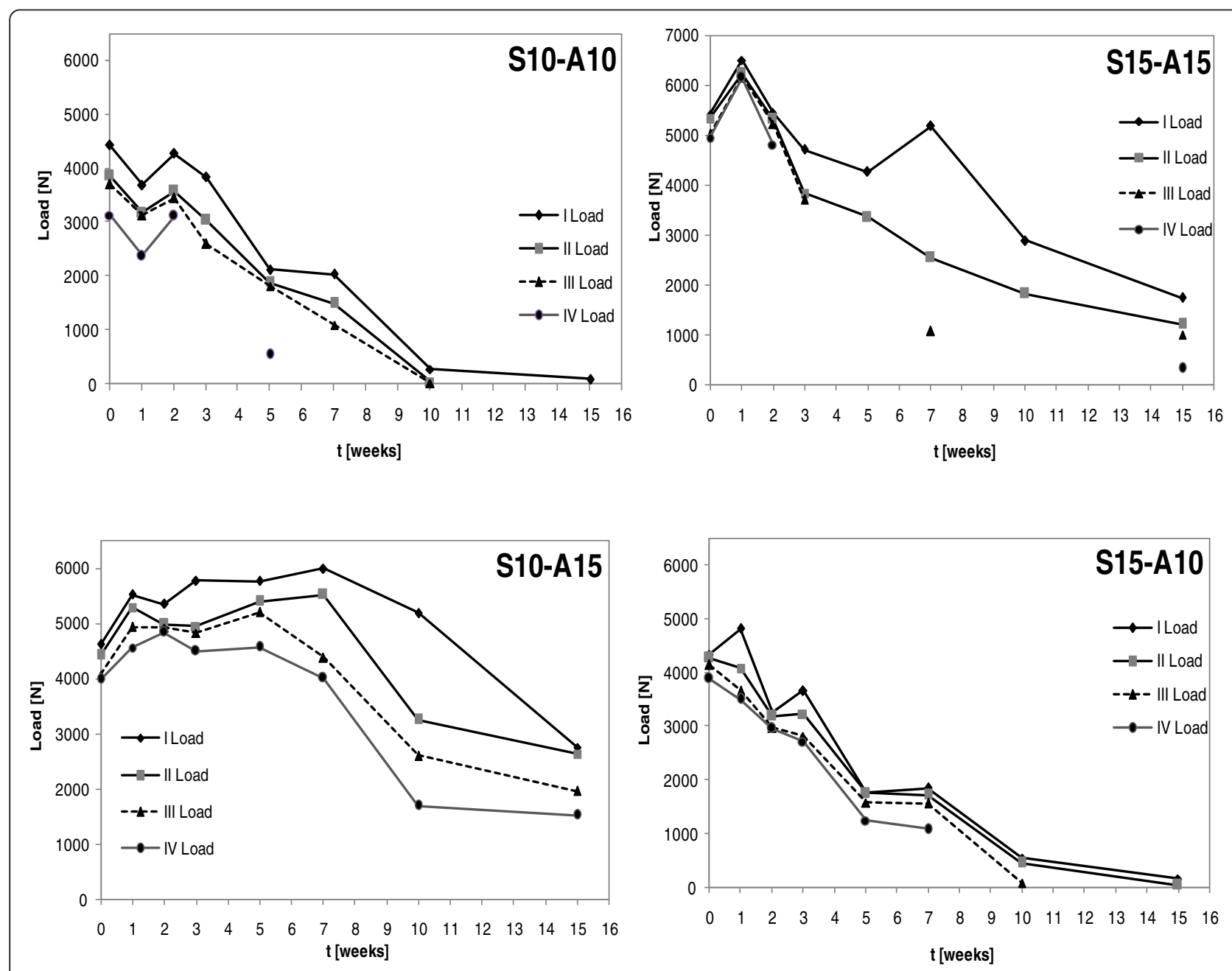

Fig. 7 Ordered load at each exposure time for all joint configurations 
reduction of resistance of the joint. Depending if one of these two phenomena is predominant, we can observe an enhancement or decrease of joint performance. Of course, the set characterized by thinner aluminium sheet evidenced a gradual reduction of the mechanical strength with increasing ageing time due to the prevalence of thinning induced by aluminium corrosion.

Samples with thicker aluminium sheet S15-A15 and S10A15 batches are less sensible to thinning phenomenon, and the layer of oxides at the metal interface is able to exert its action to enhance the joint resistance. In fact, for S10-A15 samples, during the first 7 weeks, stable mechanical performances were observed.

The S15-A15 joints, despite the high thickness of the aluminium sheet, do not maintain high load peaks at longer ageing times, such as S10-A15 set. This behaviour is due to the presence of usual defects on the rivet tail, probably generated during the riveting process, determining the premature cracks propagation at lower load. At medium ageing, the samples have undergone mainly corrosion effects with a particular stress state under the head of the rivet that cause its rupture.

Interesting consideration can be extrapolated comparing the average failure load at increasing ageing time for all joint configurations.

The trend of the S15-A10 set in Fig. 8 is typical of a joint undergone ageing treatment; in fact, the mean load values decrease gradually at increasing ageing time. Similarly the S10-A10 trend decreases with one exception between the first and the second ageing week in which the load decreases about $10 \%$ compared to the un-aged samples. The S10-A10 and S15-A10 trends exhibit the lowest load values than those of other joint combinations. The thin thickness of the aluminium lower plate, on the one hand, facilitates the embedment of the rivet through it; on the other hand, it is more subject to degradation phenomena decreasing consequently the resistance of these batches.

Effectively for long ageing times, the mechanical characteristics of these joints are compromised for the advanced state of the aluminium deterioration. For the S10-A15 and S15-A15 batches at 1 week, the joint strength is improved due to the deposit of oxides at the metal interface. In fact, the presence of a thin layer of oxides acts as adhesive interlayer improving the resistance of the joint. In this sets, the higher thickness of the bottom aluminium sheet will be less subject to deterioration. The failure primarily will be due to the activation of cracks on the rivet bottom leading to nettension failure. At 15 weeks of ageing time, only the S15-A15 and S10-A15 samples showed appreciable failure load. The other ones evidenced very poor performance, confirming a deep degradation state of these joint sets.

\section{Statistical analysis}

\section{Two-way (analysis of variance) ANOVA}

Because the data are balanced (four replicates for each case study) and the factors are fixed, the two-way analysis of variance was applied. The factors considered are the combination of thicknesses (S10-A10, S15-A15, S10A15, S15-A10) and the ageing times $(0,1,2,3,5,7,10,15)$. In the following, they are called respectively thickness $(1,2$, $3,4)$ and weeks $(1,2,3,4,5,6,7,8)$.

Table 3 shows the results of the ANOVA that allows verifying the significance of the parameters (i.e. thickness and weeks) and their interaction. Such analysis allows concluding that both the parameters are significant factors $(P<0.05)$; the lower is the $P$-value, the more the effect of the parameters is significant affecting the value of joint resistance. The statistical analysis allows to distinguish when variations in the data are effectively changed

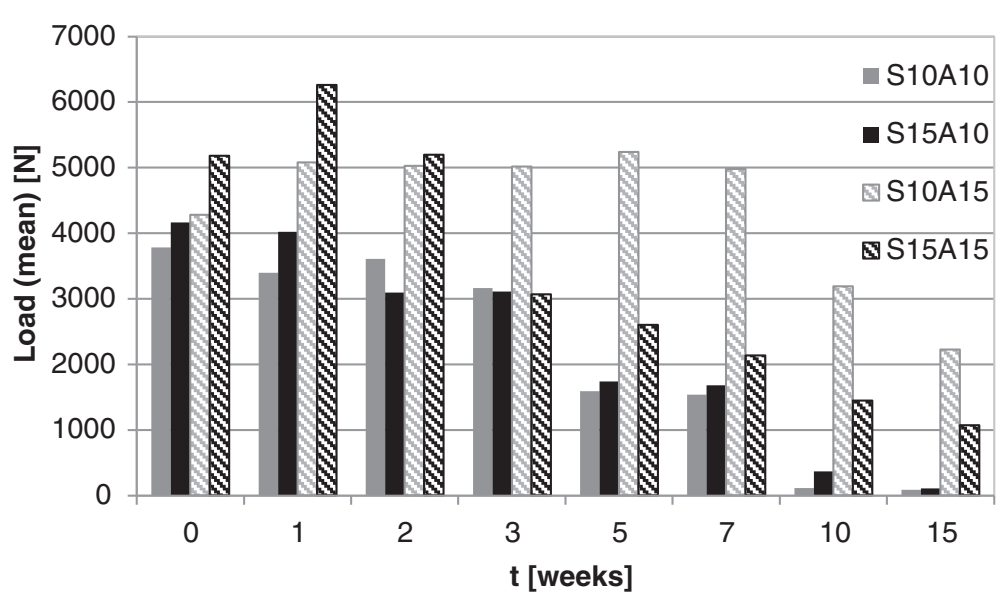

Fig. 8 Average maximum load versus ageing time for each configuration joints 
Table 3 Two-way ANOVA

\begin{tabular}{llllll}
\hline Source & DF & SS & MS & F & $P$ \\
\hline Thickness & 3 & 129963775 & 43321258 & 162.76 & 0.000 \\
Weeks & 7 & 216833489 & 30976213 & 116.38 & 0.000 \\
Interaction & 21 & 33075550 & 1575026 & 5.92 & 0.000 \\
Error & 96 & 25551921 & 266166 & & \\
Total & 127 & 405424735 & & & \\
S=515.9 & & R-Sq=93.70\% & R-Sq (adj) $=91.66 \%$
\end{tabular}

$D F$ degrees of freedom, $S$ sums of squares, $M S$ mean square, $F$ F-statistic, $P p$-value

by the outcome of one factor or lie into a variability range that belongs to the experimental errors.

The degree of significance for the factors is evident from the corresponding graphs, showed in Fig. 9 (analysis of mean). It shows both the interaction effect and main effect of the two parameters. An interaction is present when the response at a factor level depends upon the level of other factors. The graph displays each factor level mean, the overall mean, and the decision limits. If a point falls outside the decision limits, evidence then exists that the factor level mean, represented by that point, is significantly different from the overall mean. With a two-way ANOM, one has to look at the interaction effects first. If there is significant evidence for interaction, it usually does not make sense to consider main effects separately, because the effect of one factor depends upon the level of the other. In this case, we can observe an interaction effect confirming the experimental evidence that at the same ageing time, the increase (or decrease) of load depends on the thickness combination. The lower two plots show the means for the levels of the two factors, with the main effect being the difference between the mean and the centre line. They confirm that thickness and weeks are statistical significant parameters (data lying outside the range of confidence), i.e. each joint configuration is significantly different from the others in terms of the SLJ resistance and that ageing time significantly affects each configuration of studied joints.

\section{Tukey $95 \%$ test simultaneous confidence intervals}

By performing the Tukey $95 \%$ test simultaneous confidence intervals that realizes all pairwise comparisons among levels of weeks, with individual confidence level = 99,75\%, we obtained Fig. 10 in which, the load values at "Weeks" $=1$, subtracted from all the others $(\Delta \mathrm{P})$, are reported against the week increment ( $\Delta$ weeks). We can observe that the distribution of "difference of the loads" has the mean value near to zero, namely it is not possible to discriminate whether the load is different from the one at 0 week, i.e. the SPR joint resistance does no vary significantly at increasing ageing time.

These graphs allow highlighting where the joint resistance is significantly different from the un-aged ones due to the corrosive mechanisms: it is possible to identify a first stage (pre-ageing) where the value load is not statistically different from 0 week one. A second stage (transition) can be identified when a deep decay (when the $\Delta \mathrm{P}$ interval is external to the " 0 line") is attained and a third one (post-ageing) where a complete loss of load carrying capability was found. The amplitudes of three clusters related with the mechanical degradation for all configurations joints are different. These results obtained through

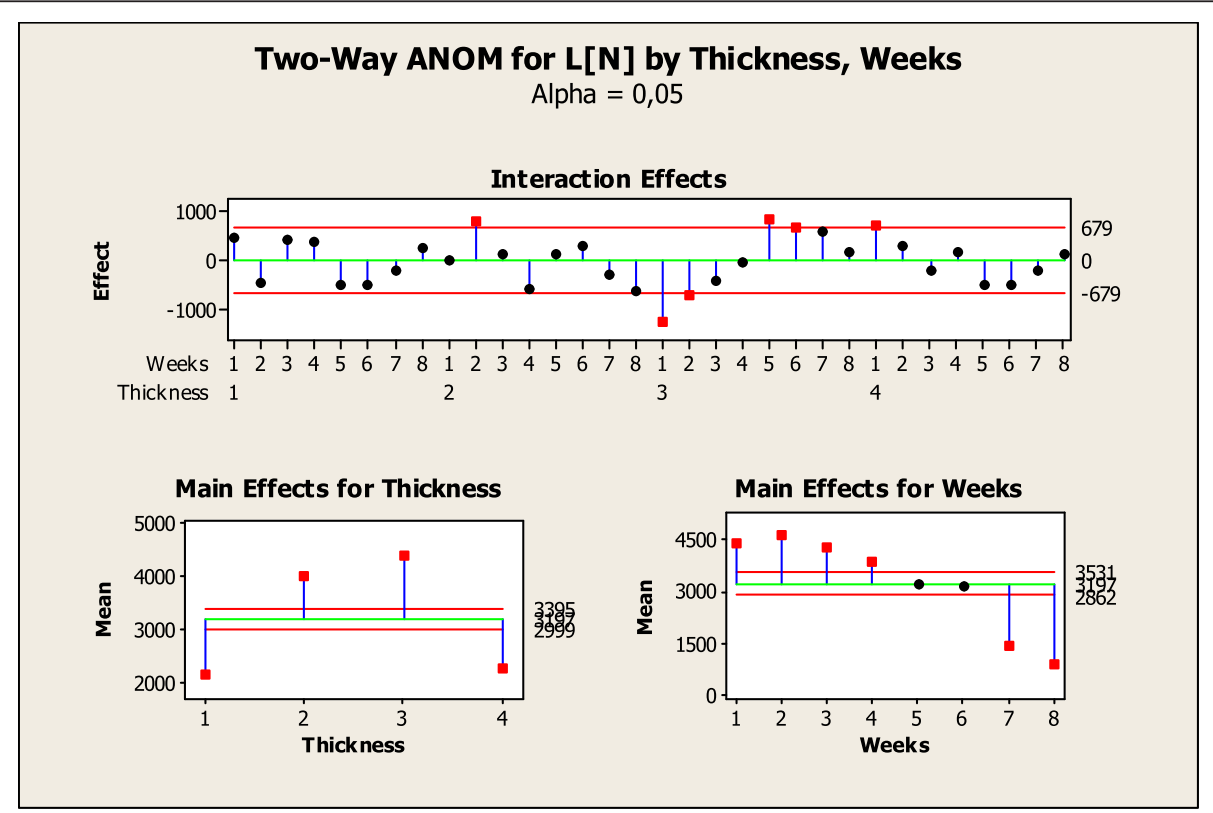

Fig. 9 Two-way ANOM for the load parameter by thickness and weeks 


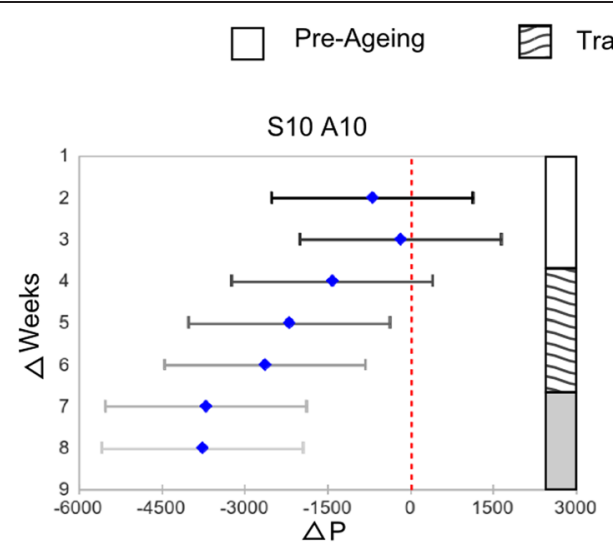

\section{Transition $\quad \square$ Post-Ageing}
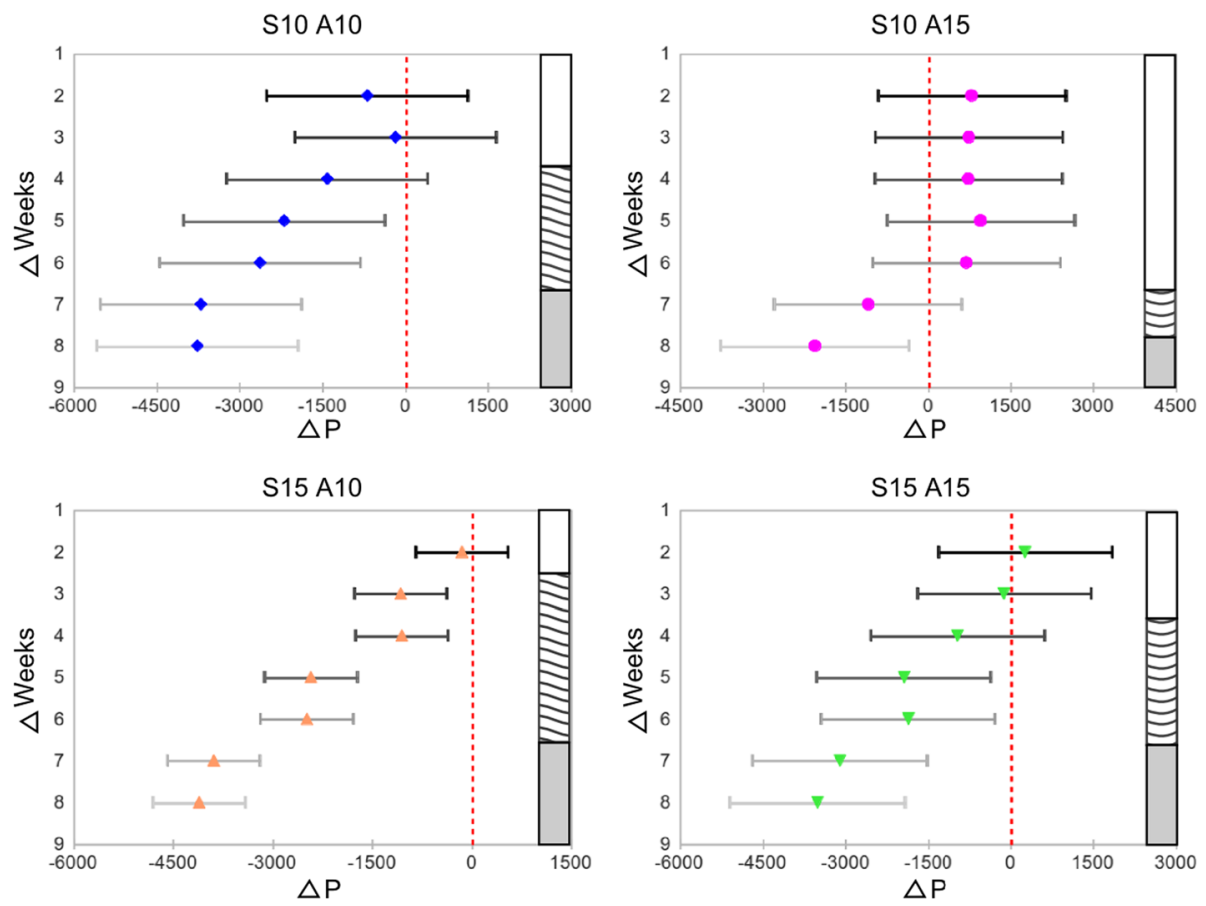

Fig. 10 Tukey $95 \%$ simultaneous confidence intervals for all thickness

statistical methods highlight the information that it was not possible to derive from the simple observation of the experimental data (see Fig. 8). In particular, it shows a difference between S10-A10 and S15-A10 related to the different variability of results, i.e. the area of pre-ageing of S10-A10 joints is more extensive than one of S15A10. This latter shows a large transition zone in which the decay of failure load is gradual, starting after 2 weeks of ageing. The trend of $\Delta \mathrm{P}$ from the transition zone to the post-ageing is similar, because the loss of resistance is mainly due to the rapid evolution of the thinning of the lower sheet. The S10-A15 joints present the widest pre-ageing zone compared to other samples. This reveals that, among the other joint combinations, this set has a good durability in aggressive environmental conditions thanks to optimal compromise between manufacturing stacking sequence and aluminium sheet thickness. In fact, the unbuttoning is the predominant failure mode up to seven ageing weeks. During riveting, the rivet, penetrating in an upper thin steel thickness, deforms properly into the lower aluminium sheet ensuring a tight connection in the overlap region. In this way, the interstices between the plates are not well geometrically identifiable. Consequently, the samples evidence a higher resistance to crevice corrosion and a time delay to have the typical bulging corrosion area (the thickening of corrosion products within the overlapped steel/aluminium interface) of single-lap joint is observed. For S10-A15 samples, the main degradation phenomena are related to galvanic corrosion instead to crevice. In the steel/aluminium galvanic couple, the aluminium is the anodic region where the metal dissolution takes place. At short ageing times, a thinning of the aluminium sheet is observed; and only at high ageing times, when the thick aluminium damage is quite relevant, the mechanical stability of the joint is compromised.

It is useful to correlate the tendency to damage each joint to the specific failure mode. With this purpose, the time maps of fracture areas were made in order to discriminate the different modes of corrosion-induced damaging during the single-lap shear test.

Figure 11 shows the evolution of electrochemical corrosion on the aluminium button for all sample sets, highlighting the effects of corrosion, i.e. the increase of oxide volume in the joining area compromises the interlocking and the thinning by dissolution of aluminium for long ageing time.

In S15-Al5 set, the thinning of aluminium sheet is not significant. This set undergoes a low effect of galvanic corrosion until 3 ageing weeks (second row of Fig. 11) up to the full corrosion cracking at 10 ageing weeks (see the right image in the same row and figure). At 10 weeks, the joint damaging is quite relevant. This behaviour is influenced both by the formation of a large amount of 


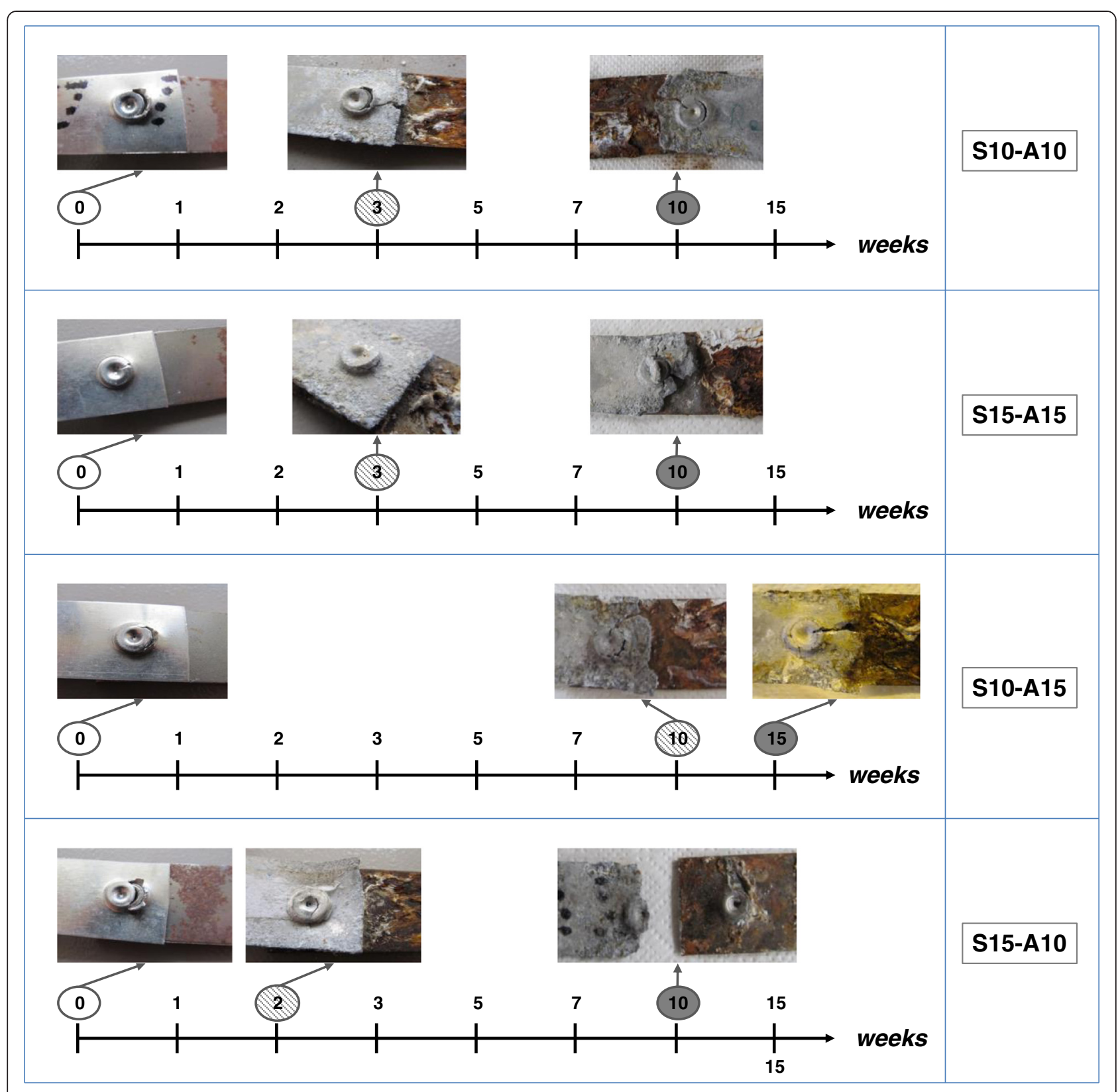

Fig. 11 Evolution of damage on aluminium button at increasing ageing time

aluminium oxides on the joint interstices and galvanic corrosion of the lower aluminium sheet. For this configuration, with a total thickness of $3.0 \mathrm{~mm}$, the rivet deformation on the lower sheet is not optimal. Consequently, this set is sensible to premature failure mechanism stimulated by corrosion phenomena. At increasing ageing time, we observed a transition from unbuttoning to cleavage of aluminium sheet at very low load magnitude.

Differently, the S10-A15 set shows significant effects of galvanic corrosion from the tenth ageing weeks (third row of Fig. 11) up to the complete corrosion cracking at 15 weeks.
Instead, the S10-A10 joints are heavy influenced by the thinning of aluminium sheet induced by galvanic corrosion. Just after 3 ageing weeks (first row of Fig. 11), the corrosive attack on aluminium is more advanced. The cracks, generated during the manufacturing procedure or by corrosion attack, propagate respectively from aluminium button and the sheet edges. Finally, the aluminium button has very low performances and the rivet, subject to shear force, induces bearing at the aluminium hole. In this way, the rivet tail is pulled out from its seat. 
The beginning of the ageing transition for the S15A10 joints is anticipated at the second ageing week (the last row of Fig. 11) leading to unbuttoning failure.

At 10 ageing weeks, both S10-A10 and S15-A10 (first and fourth row of Fig. 11) joints fail due to significant corrosive attack on aluminium sheet. In fact, these joint sets, realized with a low thickness of aluminium sheet $(1.0 \mathrm{~mm})$, are more exposed to localized corrosion. The electrochemical exfoliation of the aluminium sheet induces a heavy reduction of its cross-section, decreasing consequently the failure load. The presence of cracks or defects on the button aluminium stimulates the corrosion phenomena accelerating the degradation of the joint.

By comparison of joint sets, only the S10-A15 samples are able to be used in very aggressive environmental conditions. The shear resistance is stable in a large range of ageing time in salt spray fog test. Only at about 10 weeks, the degradation phenomena influence their performances. After 15 weeks of ageing, their resistance was reduced to about $50 \%$, despite other joint sets that evidenced a performance reduction of about $80-95 \%$.

\section{Conclusions}

In this work, the durability on salt fog spray test of selfpiercing riveted joint with four different thickness configurations has been evaluated. The purpose was to evidence the relationship between corrosive degradation and joint design (materials, geometry, performances, etc...). The experimental results evidenced that the corrosion degradation phenomena influenced significantly both the performance and failure mechanisms of the joints; also, the joint configuration is a significant factor for the corrosion effect.

In the salt spray, the aluminium sheet undergoes a noticeable degradation due to galvanic $\mathrm{Al} / \mathrm{Fe}$ corrosion. At first, the presence of aluminium hydroxides influences the SPR joint interlocking. When the oxide layer is thin, an unexpected improvement of the interlocking was observed in which the failure load is quite similar than the un-aged samples. At increasing the thickness of the oxide layer, its brittle failure is favoured. The crevice at the aluminium/ steel interface becomes larger, and subsequently the aluminium plate is subjected to a progressive thinning influencing significantly the failure mechanism of the joint. The degradation is more evident for the samples characterized by a thinner aluminium sheet.

Statistical analysis confirms that both the four "thickness" combinations and "ageing time" are the significant factors. Comparing the ANOVA results was possible to confirm the effect of the ageing on the performance of the joint. Furthermore, it was possible to relate, for each joint configuration, failure mechanism clusters with specific mechanical/corrosion phenomena.

\section{Competing interests}

The authors declare that they have no competing interests.

\section{Authors' contributions}

LC carried out the durability tests in salt spray environment and investigated the corrosion phenomena and the joints' failure modes, EP defined the durability conditions, analyzed the results and revised the manuscript, GDB defined the Design of Experiments (DOE), analyzed the data of mechanical tests and developed the statistical analysis, GG performed the mechanical tests on the joints and elaborated the data, CB studied the joints' configurations, analyzed the results, investigated the joints' failure modes and revised the manuscript. All authors read and approved the final manuscript.

\section{Author details}

${ }^{1}$ Department of Industrial Chemistry and Materials Engineering, Faculty of Engineering, University of Messina, Contrada di Dio, 98166 Messina, Italy. ${ }^{2}$ CNR ITAE, Via Salita Santa Lucia sopra Contesse 5, 98126 Messina, Italy. ${ }^{3}$ Department of Civil Engineering, Computing, Construction, Environmental and Applied Mathematics, University of Messina, Contrada di Dio, 98166 Messina, Italy.

Received: 16 February 2015 Accepted: 11 May 2015

Published online: 16 June 2015

\section{References}

Azzerri, N, Bruno, R, Ferrari, V, et al. (1982). Electrochemical test methods for the development of coated steels with improved corrosion resistance practical application to food packaging and automotive industry products. Material Chemistry 7:221-239. doi:10.1016/0390-6035(82)90082-7

Bardal, E. (2004). Corrosion and protection. 315

Barnes, TA, \& Pashby, IR. (2000). Joining techniques for aluminum spaceframes used in automobiles. Part 11 - adhesive bonding and mechanical fasteners. Journal of Material Processing Technology, 99, 72-79. doi:10.1016/S0924-0136(99)00361-1.

Bellinger, NC, Komorowski, JP, \& Gould, RW. (2007). Corrosion pillowing in aircraft fuselage lap joints. Journal of Aircraft, 44, 758-763.

Borsellino, C, \& Di Bella, GRV. (2008). Il collegamento meccanico di leghe di alluminio: nuove tecnologie a confronto. Lamiera, 4, 114-122.

Calabrese, L, Bonaccorsi, L, Proverbio, E, et al. (2013). Durability on alternate immersion test of self-piercing riveting aluminium joint. Materials and Design, 46, 849-856. doi:10.1016/j.matdes.2012.11.016.

Calabrese, L, Proverbio, E, Pollicino, E, et al. (2014a). Effect of galvanic corrosion on durability of aluminium/steel self-piercing rivet joints. Corrosion Engineering, Science and Technology, 1743278214Y, 000. doi:10.1179/ 1743278214 Y.0000000168.

Calabrese, L, Proverbio, E, Galtieri, G, \& Borsellino, C. (2014b). Effects of ageing on mechanical durability of round clinched steel/aluminium joints. Int J Mech Mater Eng, 9, 23. doi:10.1186/s40712-014-0023-6.

Calabrese, L, Proverbio, E, Di Bella, G, et al. (2015). Failure behaviour of SPR joints after salt spray test. Engineering Structures, 82, 33-43. doi:10.1016/ j.engstruct.2014.10.020.

Carle, D, Blount, G (1999). The suitability of aluminium as an alternative material for car bodies. Material Design 20:267-272. doi:10.1016/S0261-3069(99)00003-5

Chrysanthou, A (2014). Self-piercing riveting. Self-Piercing Riveting 41-55. doi:10.1533/9780857098849.1.41.

Di Bella, G, \& Calabrese, L. (2010). Pin-contact behaviour of composite sandwich structures under compressive bearing load. Applied Composite Materials, 18, 197-210. doi:10.1007/s10443-010-9146-y.

Esfahani, M, Durandet, Y, Wang, J, \& Wong, YC. (2012). Effect of joining process on the coatings of self-piercing rivets. Advanced Materials Research, 488-489, 1501-1505. doi:10.4028/www.scientific.net/AMR.488-489.1501.

Feser, R, \& Klose, SG. (1999). Mischbauweise im Automobilbau Oberflächenvorbehandlung und Korrosionsschutz. Materials and Corrosion, 50, 470-474. doi:10.1002/(SICI)1521-4176(199908)50:8<470::AIDMACO470>3.0.CO;2-X.

Fiore, V, Alagna, F, Di Bella, G, \& Valenza, A. (2013a). On the mechanical behavior of BFRP to aluminum AA6086 mixed joints. Compos Part B Eng, 48, 79-87. doi:10.1016/j.compositesb.2012.12.009.

Fiore, V, Alagna, F, Galtieri, G, et al. (2013b). Effect of curing time on the performances of hybrid/mixed joints. Compos Part B Eng, 45, 911-918. doi:10.1016/j.compositesb.2012.05.016. 
Fujita, S, \& Mizuno, D. (2007). Corrosion and corrosion test methods of zinc coated steel sheets on automobiles. Corrosion Science, 49, 211-219. doi:10.1016/j.corsci.2006.05.034.

González-García, Y, González, S, \& Souto, RM. (2007). Electrochemical and structural properties of a polyurethane coating on steel substrates for corrosion protection. Corrosion Science, 49, 3514-3526. doi:10.1016/j.corsci.2007.03.018.

Han, L, \& Chrysanthou, A. (2008). Evaluation of quality and behaviour of self-piercing riveted aluminium to high strength low alloy sheets with different surface coatings. Materials and Design, 29, 458-468. doi:10.1016/ j.matdes.2006.12.020.

Han, L, Chrysanthou, A, \& Young, KW. (2007). Mechanical behaviour of selfpiercing riveted multi-layer joints under different specimen configurations. Materials and Design, 28, 2024-2033. doi:10.1016/j.matdes.2006.06.015.

Han, L, Thornton, M, \& Shergold, M. (2010). A comparison of the mechanical behaviour of self-piercing riveted and resistance spot welded aluminium sheets for the automotive industry. Materials and Design, 31, 1457-1467. doi:10.1016/j.matdes.2009.08.031.

Heinemeyer, C, \& Feldmann, M. (2011). The influence of rivet corrosion on the durability of riveted connections. Steel Constr, 4, 188-192. doi:10.1002/ stco.201110026.

Hoang, N-H, Langseth, M, Porcaro, R, \& Hanssen, A-G. (2011). The effect of the riveting process and aging on the mechanical behaviour of an aluminium self-piercing riveted connection. Eur J Mech - A/Solids, 30, 619-630. doi:10.1016/j.euromechsol.2011.02.006.

Huttunen-Saarivirta, E, Yudin, VE, Myagkova, LA, \& Svetlichnyi, VM. (2011). Corrosion protection of galvanized steel by polyimide coatings: EIS and SEM investigations. Prog Org Coatings, 72, 269-278. doi:10.1016/j.porgcoat.2011.04.015.

Krüger, L, \& Mandel, M. (2011). Electrochemical behaviour of aluminium/steel rivet joints. Corrosion Science, 53, 624-629. doi:10.1016/j.corsci.2010.10.015.

Kweon, JH, Jung, JW, Kim, TH, et al. (2006). Failure of carbon composite-toaluminum joints with combined mechanical fastening and adhesive bonding. Composite Structures, 75, 192-198. doi:10.1016/j.compstruct.2006.04.013.

Li, D, Han, L, Thornton, M, \& Shergold, M. (2012). Influence of edge distance on quality and static behaviour of self-piercing riveted aluminium joints. Materials and Design, 34, 22-31. doi:10.1016/j.matdes.2011.07.046.

Moroni, F, Pirondi, A, \& Kleiner, F. (2010). Experimental analysis and comparison of the strength of simple and hybrid structural joints. International Journal of Adhesion and Adhesives, 30, 367-379. doi:10.1016/j.ijadhadh.2010.01.005.

Okafor, AC, Natarajan, S (2007). Multifrequency eddy current inspection of corrosion in clad aluminum riveted lap joints and its effect on fatigue life. AIP Conf. Proc. AIP, pp 1274-1281

Patrick, EP, Sharp ML (1992). Joining aluminium auto body structure. Int. Congr. Expo. SAE. Detroit, Michigan, p Technical Paper n. 920282.

Valenza, A, Fiore, V, Borsellino, C, et al. (2007). Failure map of composite laminate mechanical joint. Journal of Composite Materials, 41, 951-964. doi:10.1177/0021998306067257.

Wood, PKC, Schley, CA, Williams, MA, \& Rusinek, A. (2011). A model to describe the high rate performance of self-piercing riveted joints in sheet aluminium. Materials and Design, 32, 2246-2259. doi:10.1016/j.matdes.2010.11.018.

Zhao, H, White, DR, \& DebRoy, T. (1999). Current issues and problems in laser welding of automotive aluminium alloys. International Materials Review, 44, 238-266. doi:10.1179/095066099101528298.

Zheng, WY, Derushie, C, Lo, J, \& Essadiqi, E. (2007). Corrosion protection of joining areas in magnesium die-cast and sheet products. Materials Science Forum, 546-549, 523-528. doi:10.4028/www.scientific.net/MSF.546-549.523.

\section{Submit your manuscript to a SpringerOpen ${ }^{\circ}$ journal and benefit from:}

- Convenient online submission

- Rigorous peer review

- Immediate publication on acceptance

- Open access: articles freely available online

- High visibility within the field

- Retaining the copyright to your article

Submit your next manuscript at $>$ springeropen.com 